\title{
Medical education in Nepal during the COVID-19 pandemic: challenges and opportunities
}

\author{
Nuwadatta Subedi, ${ }^{1 *}$ (iD Sabita Paudel ${ }^{2}$ iD \\ 'Department of Forensic Medicine, ${ }^{2}$ Department of Pharmacology, Gandaki Medical \\ College Teaching Hospital and Research Center, Pokhara
}

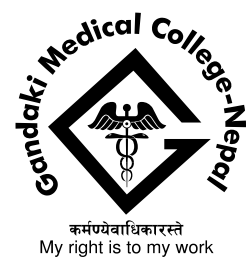

Journal of GANDAKI MEDICAL COLLEGENEPAL (J-GMC-N)

J-GMC-N | Volume 13| Issue

02| July-December 2020

\section{Correspondence to:}

Dr Nuwadatta Subedi

Department of Forensic

Medicine, Gandaki Medical

College Teaching Hospital and

Research Center, Pokhara

E mail: drndsubedi@gmail.com

DOI: $\underline{10.3 \mid 26 / \text { igmen.v| } 3 \mathrm{i} 2.33168}$
Medical courses are designed by incorporating several aspects of teaching and learning including lectures, preclinical laboratory exercises, community field postings, clinical postings, compulsory rotatory internships etc. They are multidimensional and multifaceted. The aim of the course is to produce competent medical personnel who can deliver health care in respective fields with some set standards of knowledge and skills. The graduates should also possess empathetic and compassionate attitude towards the patients, attendants and colleagues. In order to do this, they need competence in various theoretical, practical, clinical as well as soft skills like counselling and communication. ${ }^{1}$

Every part of medical course is important to produce competent graduates. This has called for the design of competency-based curriculum, focusing on variety of learning methods like didactic lectures, problem based learning, videos, simulation, skills laboratory, demonstrations, history taking, patient examinations, laboratory exercises etc. ${ }^{2}$ Whatever way we design them, it is not easy to incorporate all the aspects of learning and this is a major concern for medical educationist in the world today.

COVID-19 has caused a great impact on peoples' mobility and education sector is among the most highly affected. Any compromise in shaping the future health care professionals would result in a huge loss, especially in a scenario where there has been a high demand for them. There is a concern whether the crisis, if persistent, will fundamentally alter medical education. ${ }^{3}$ Due to this, world-wide researches have been done on effective online learning. The guidelines of country-wide lockdown initially and the need for physical distancing has made it impossible to continue regular physical classes, clinical postings and practical exercises. While all the educational activities including the University examinations were put to halt during the initial days of COVID-19 crisis, medical universities still seem to be at a loss on how to resume classes. Gradually, online classes have been started and different software are being used to deliver classes mostly theory based.

Though online classes appear to be the only suitable modality of resumption and continuation of educational activities for now, the effectiveness of classes with only a single form of learning (didactic lecture) for a long duration seems questionable. There is a need for some improvement in the form of delivery of online classes. ${ }^{4}$ Universities need to incorporate learning methods like problem-based learning, case-based learning and team-based learning. These methods can be performed online without much inconvenience. They 
will engage students and motivate them for active learning. As proven by many studies, they are better strategies than didactic lectures. ${ }^{5,6}$ Traditional teaching through online learning has a disadvantage of being less interactive, which poses a risk of decreasing students' concentration and eventually learning. We also need to focus on practical and clinical aspects of learning along with theory classes. These are better clarified and elucidated with newer learning strategies. As medical teachers, we have experienced that there is a limited scope in online learning, so we need to bring the best out of it.

The postponed examinations were rescheduled by most of the institutes in Nepal and attempts of resumption of clinical postings and practical classes were made but the surge in number of COVID-19 cases have limited their feasibility and again the activities have been halted in many institutes. This situation has created a concern regarding the quality of education, extension of graduation, financial obligations and psychological well-being of students at large. Recent advancements in technology, however, have made it possible to fill this void. The universities should therefore now also focus on imparting the non-theoretical skills. The use of virtual reality techniques have already been tried successfully at different setups. ${ }^{7}$

These technologies can be used for better learning and can even act as alternatives to the existing teaching modalities not only during this pandemic but at all times. It is high time that the universities with technical support from experts develop different learning management systems and software to conduct practical classes and examinations. The rest of the world is a step ahead of us and it would not take much effort to learn from scholars around the globe.

\section{REFERENCES:}

1. Douglas AH, Acharya SP, Allery LA.Communication skills teaching and learning in Nepal; what are medical students' perceptions and experiences? A qualitative study. BMC Med Educ. 2020;20(1):111. DOI: $10.1186 / \mathrm{s} 12909-020-02330-y$ PMID: 33121504.

2. Whitcomb ME. Competency-based graduate medical education? Of course! But how should competency be assessed. Acad Med. 2002;77(5):359-60. DOI: 10.1097/00001888200205000-00001 PMID: 12010688.

3. Wayne DB, Green M, Neilson EG. Medical education in the time of COVID-19. Sci Adv. 2020;6(31):4-6. DOI: $10.1126 /$ sciadv.abc7110 PMID: 32789183.

4. Tuladhar SL, Pradhan D, Parajuli U, Manandhar P, Subedi N. Study on the effectiveness of online classes for undergraduate medical and dental students of Gandaki Medical College during COVID 19 pandemic period in Nepal. Orthod J Nepal. 2020;10(2):36-40. DOI: 10.3126/ojn. v10i2.31146

5. Dennis J. Problem-Based Learning in Online vs. Face-to-Face Environments. Educ Health (Abingdon). 2003 Aug 1;16:198-209. DOI: 10.1080/1357628031000116907 PMID: 14741905.

6. Whittaker A. Effects of Team-Based Learning on Self-Regulated Online Learning. Int J Nurs Educ Scholarsh. 2015 Jan 10;12. DOI: 10.1515/ ijnes-2014-0046 PMID: 25860866.

7. Chen S, Zhu J, Cheng C, Pan Z, Liu L, Du J, et al. Can virtual reality improve traditional anatomy education programmes? A mixed-methods study on the use of a 3D skull model. BMC Med Educ. 2020;20(1):1-10. DOI: 10.1186/s12909-02002255-6 PMID: 33129310. 